\title{
The cleaning of ward floors and the bacteriological study of floor-cleaning machines
}

\author{
J. G. BATE
}

From the Department of Pathology, The Princess Louise Kensington Hospital for Children, London

SYNOPSIS Current trends in ward flooring materials and cleaning methods are considered from the point of view of the hospital bacteriologist. Methods employed in an investigation into the bacteriological safety of a number of floor-cleaning machines are described, and some considerations governing the choice of vacuum cleaners for ward use are discussed.

The ward floor has long been recognized as a secondary reservoir of infection (Cruickshank, 1935). The extent to which contamination from this source contributes to cross-infection is not clearly definable, though it is well known that the flora of the floor is often found to reflect that which besets the occupants of the beds (Garrod, 1944), and instances have been recorded in which it has been impossible to incriminate any other source of cross-infection (Rubbo, 1948). The avoidance of needless air contamination by the adoption of good housekeeping methods is basic practice in hospitals today, and if efforts to this end are to be rightly directed and economically achieved, the hospital bacteriologist must be prepared to advise those who have responsibility on the domestic and administrative sides. They in their turn have become increasingly conscious of floor-cleaning problems as the result of labour difficulties, workstudy investigations, and pressures by those commercially interested in floors and floor cleaning.

Information on which to base such advice is not to be found amid the usual daily reading of most bacteriologists, and therefore the following summary of current developments in floor materials and cleaning methods may be found useful for reference. The bacteriologist is often asked to advise about the safety, from the cross-infection aspect, of vacuum cleaners and floor-cleaning machines, and lacking the time to develop a satisfactory technique for eliciting the necessary evidence, may fall back on methods which give results of which the accuracy is far removed from that found in his more ordinary investigations. An account is therefore given of methods used to study this problem in a recent investigation on behalf of the Division of Hospital Facilities of King Edward's Hospital Fund for London, the results of which are published elsewhere (Bate, 1961).
FLOORING MATERIALS

wooD Of the types of flooring materials that have been used in the past for hospital wards, probably the most popular has been wood block or wood strip. Such flooring is undoubtedly attractive and . long wearing, but it is porous, and the surface is broken between the strips or blocks by crevices which retain dust. The application of seals to these floors instead of polish is at present gaining popularity, though not all seals give equally satisfactory results. But there seems little doubt that these finishes will be generally used on account of their non-slip qualities, their effective filling of pores and crevices, and their labour-saving potentialities. There are about 40 훙 different types of seal available at present, and the Timber Development Association has published an informative booklet about them. ${ }^{1}$ This subject is also being investigated by the Division of Hospital $\stackrel{3}{.}$. Facilities of the King's Fund, and a report on the trials of various seals and polishes in hospital wards will in due course be made available.

MAINTENANCE OF SEALED FLOORS Sealed floors can be simply maintained by vacuum cleaners or impreg- No nated mops, with damp mopping occasionally to clean any unusual soiling. The life of the seal may be $\mathcal{O}$ prolonged by the application of a suitable emulsion $\mathrm{N}$ polish, and this can be a factor of considerable importance in hospital wards, which may be in constant 0 use for years on end without any opportunity for $\bar{\varnothing}$ renewing the seal. Some seals are more difficult to $\stackrel{\mathcal{P}}{\rightarrow}$ apply than others, when the time comes for the re- $\frac{T}{0}$ newal of worn areas. Thus the hospital's initial

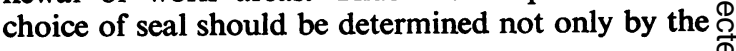

'The Timber Development Association's booklet on floor seals is known as Information Bulletin $\mathrm{C} / 1 \mathrm{~B} / 3$, and is published by the Association at 21 College Hill, E.C.4. 
lasting qualities of the seal, but also by the standard of the staff available for re-applying it. It is not generally practicable to re-seal worn areas while the ward is occupied, partly because of the smell, and partly because of the need to shut off areas of the ward while the fresh seal is drying. The worn areas are always in the busiest parts.

LINOLEUM After wood, linoleum has probably been the most widely used flooring material for wards, either as continuous sheet or as tiles. It is semiporous, and is often wax polished, but can be effectively sealed to prevent the treading in of dirt and to make for easier maintenance. Non-slip, resinemulsion polishes can be applied from time to time, as for sealed wooden floors; these need relatively little buffing, so that daily maintenance is confined to removing dust with vacuum cleaner or impregnated mop and removing adherent soiling by damp mopping with antiseptic detergent when required.

RUBBER Rubber flooring is still quite widely used in hospitals, and it has many good qualities. However, it is relatively expensive, and it seems possible that some of the newer types of plastic materials may provide as high a standard of flooring at lower cost.

PLASTIC FLOORING In more recent years, rapid progress has been made with the development of thermoplastic 'asphalt', vinyl asbestos, and polyvinylchloride (P.V.C.) flooring materials. Polyvinylchloride in particular seems to have considerable advantages. It has resilience and a naturally tough impervious surface, non-slip when dry. Adjacent sheets can be welded together to give a surface which is continuous from wall to wall. Emulsion polishes can be applied occasionally, otherwise daily maintenance needs only a vacuum cleaner or impregnated mop. It also lends itself particularly well to dampcleaning and flooding techniques, which are discussed below. Vinyl asbestos has rather similar properties but cannot be welded. Thermoplastic 'asphalt' tiles are cheap and hard wearing, but perhaps less suitable for wards as they are relatively noisy and less resilient.

TERRAZzo This material is unlikely to be laid in wards to any extent, as it is hard, noisy, and unless underfloor heating is provided, cold. But if laid with regard to certain conditions (fall towards a gutter ensured, safeguards against leakage, use of built-in furniture cantilevered from the walls and clear of the floor) it can form the basis of a system of floor cleaning by flooding with water from strategically-placed nozzles. Such a system has been in use for six years in the Out-patient Department of The Hospital for Sick Children, Great Ormond Street, London. In that setting it has worked well, and it is conceivable that the system might find an application in special places, such as dressing-rooms, where the need to apply stringent cleaning methods at frequent intervals was felt to outweigh the obvious difficulties.

\section{CURRENT TRENDS IN FLOOR CLEANING METHODS}

VACUUM CLEANING AND POLISHING The danger of sweeping with ordinary brooms needs no mention here, but sweeping mops and cloths impregnated with dust-retaining oils have recently been introduced as alternatives to the almost universal vacuum cleaner. It is said that these are efficient sweepers that do not disturb floor dust, but whether they remove it as efficiently as vacuum cleaners do, and whether they tend to leave behind a film of oil which may in time make the floor retain dust are questions which are not yet answered. Vacuum cleaners, on the other hand, leave no doubt of their efficiency when they are properly maintained. The same cannot be said of suction polishers in their present form. One type of these machines has rotating brushes which tend to cause centrifugal dispersal of dust unless the surrounding flanges are adjusted accurately to the floor. Most domestics have no idea that these flanges are anything other than buffers. The cloth dust bags are quite ineffective in retaining bacteria-carrying particles (Bate and James, 1958), and though paper bags are now fitted as well, these are not often emptied, and are frequently found to be torn and useless.

So far as hospital wards are concerned, it is most desirable that the use of floor-polishing machines should be reduced to a minimum, partly because of the noise and disturbance they cause, and partly because of the time it takes to carry out the polishing procedures with these machines. In this connexion, the production of self-burnishing emulsion polishes is a welcome development that may lead to greater simplification of maintenance routines for linoleum, rubber, and plastic floors and for sealed wood floors. These polishes are applied to the floor by spray, lambswool applicator, or similar device, and are said to need no mechanical burnishing at all, and renewal only at intervals of several weeks, depending on traffic.

WET CLEANING AND DRY CLEANING Damp mopping can be highly effective so long as the mops are kept clean and enough antiseptic detergent is used to ensure effectiveness up to the end of the operation. An improvement on this technique is that of flooding and wet pickup, originating in the United States. 
This can either be part of a regular routine as a supplement to damp mopping, or reserved for terminal disinfection. After removing the furniture, several litres of an antiseptic detergent solution are poured on to the centre of the floor and spread out to the walls by a clean mop, and subsequently dried off by a wet pick-up vacuum cleaner. Machines of this kind, having a hose and nozzle, are now available in Great Britain, and seem more convenient for the purpose than are the ordinary floor-drying machines.

Wet cleaning is damaging to a wax-finished floor, and is not considered advisable on sealed floors except for the occasional removal of heavy soiling. Flooding is obviously impracticable on porous or discontinuous surfaces such as timber and linoleum, where the solution may seep through. It should be reserved for impervious surfaces such as terrazzo, welded P.V.C., or other jointless composition, though it has been successfully used with plastic tiles where these have been expertly laid with waterproof adhesive.

Where wet cleaning or flooding may damage the floor surface, it may be practicable to use a drycleaning technique that involves the sprinkling or spraying of an emulsion polish on to the floor, followed by the operation of an electric polisher with a nylon or steel wool pad. This method has appeared to be successful in some hospitals, and is claimed to combine cleaning and polishing in one operation; but its bacteriological effectiveness seems to need further investigation.

SOLUTIONS SUITABLE FOR DAMP CLEANING AND FLOODING The 'black fluid' phenolic antiseptics and liquor chloroxylenolis both contain soaps and therefore have detergent as well as variable antiseptic properties, but neither is very suitable for this purpose, the one on account of its smell, and the other of its expense, and there is a need for a cheap, effective and persistent detergent antiseptic for floor hygiene. Two developments from the United States seem promising. Adams, Fahlman, Dube, Dube, and Read (1959) found a demonstrable antibacterial effect for as long as eight hours after vigorous cleaning of surfaces with a mixture of sodium benzene sulphonate, $o$-phenylphenol, and $p$-tertiary amylphenol. The iodophors, which are mixtures of iodine with non-ionic surface-active agents, as well as being detergent, are said to have powerful antiseptic effects, and to remain lethal to Staph. aureus and Salm. typhi in five minutes down to a dilution of 6 parts of iodine per million (Gershenfeld and Witlin, 1955, quoted by Sykes, 1958). A solution containing 75 parts of iodine per million has been successfully used in the flooding technique described above.
THE SAFETY OF FLOOR-CLEANING MACHINES

As has already been pointed out, among much that is changing in floor-cleaning practice, the use of vacuum cleaners for removing dust remains almost universal. Such machines have potentialities for spreading infection, and it is important to be sure that machines in use or under consideration for purchase are above suspicion in this respect. The bacteriologist asked to report on the bacterial content of the exhaust air may find it all too easy to hold a culture plate in the air stream for a short time, and later to give a report on the significance of the resulting growth. Such a proceeding is unwise for a number of reasons beside the absence of any standard for comparison. Accurate sampling is governed by very precise conditions, none of which can be observed by this makeshift method. Furthermore, the emerging jet is of high velocity and low pressure in relation to the surrounding air, which rushes in from all sides to mix with it, so that the sample must include a quantity of air which has not passed through the cleaner at all. This phenomenon, an example of the Bernouilli effect, is illustrated in Figure 1.

There is, in fact, no accurate method for sampling the bacterial content of air which is moving at anything up to 80 miles an hour. The sampling of even slow-moving air brings in aerodynamic problems which most bacteriologists will prefer to avoid. Recognition of this fact led to the conclusion that the simplest means of sampling the output from a number of vacuum cleaners would be to trap the air in a reservoir and hold it stationary while a sample was collected by a slit sampler (Bourdillon, Lidwell, Lovelock, and others, 1948).

Figure 2 illustrates the apparatus, which consists of a reservoir of approximately $20 \mathrm{cu}$. ft. capacity, made out of a $4 \mathrm{ft}$. length of heavy gauge polyethylene 'layflat' tube $9 \mathrm{ft}$. in circumference. The upper end is closed by pleating and firmly tied with string, which also suspends the bag from the ceiling. The other end is open and fixed to a stout wooden frame which can be fastened down on to the surface of a table which forms the base of the reservoir (Fig. 3).

The slit sampler stands on this table, and is thus inside the reservoir, the electrical leads and suction line being carried down through airtight openings in the table top to the air pump on the shelf below. In use, the reservoir frame is held down on to the table top by light plastic clips, strong enough to maintain an airtight joint between the surfaces, which are covered with strips of plastic foam draught excluder, but able to release the bag if overdistended. Air from vacuum cleaners under test fills the reservoir through a lightweight polyethylene tube $4 \mathrm{ft}$. in diameter and 

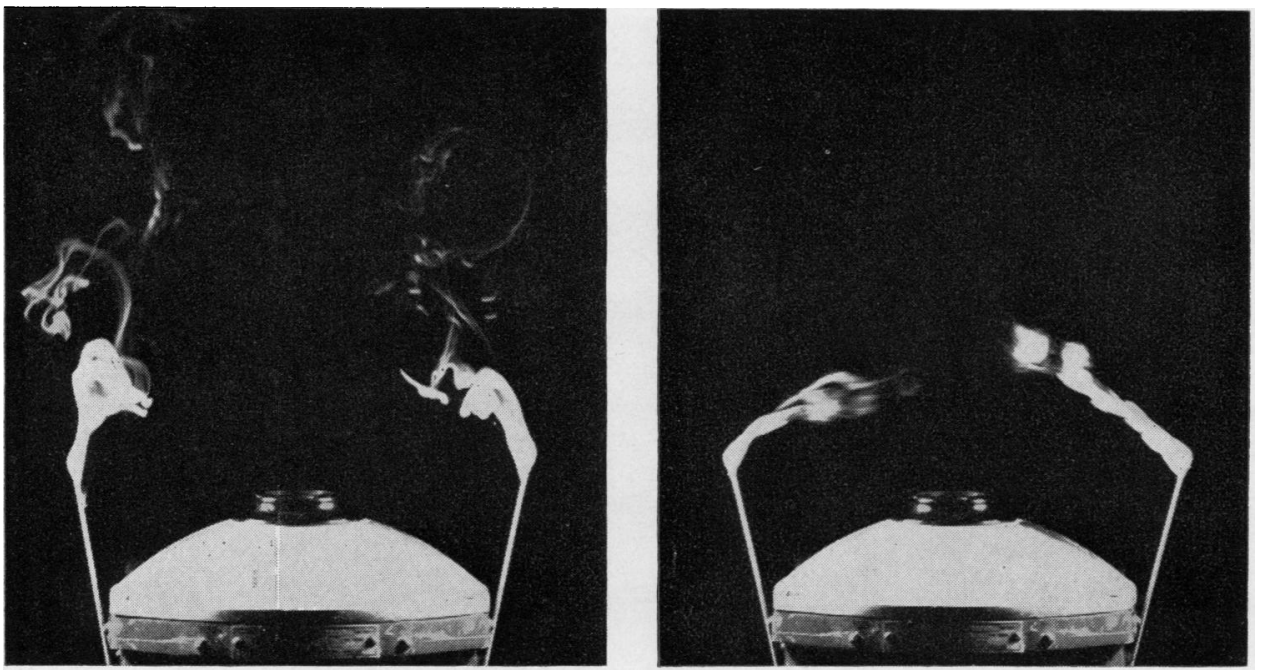

FIG. 1. Aspiration of surrounding air into the exhaust jet of a cylinder-type cleaner. On the left, the motor is stationary.

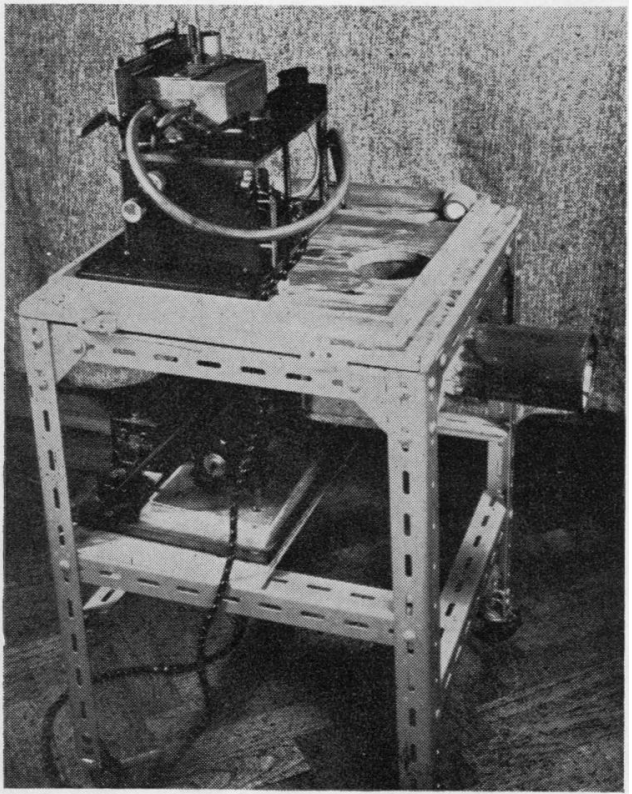

FIG. 3

FIG. 2. The apparatus in use, collecting exhaust air from a large tank-type vacuum cleaner.

FIG. 3. The table which carries the slit sampler and forms the base of the air reservoir. To the right of the slit sampler is the opening of the collecting duct.

FIG. 4. Collection of air from a small cylindertype vacuum cleaner.
FIG. 2
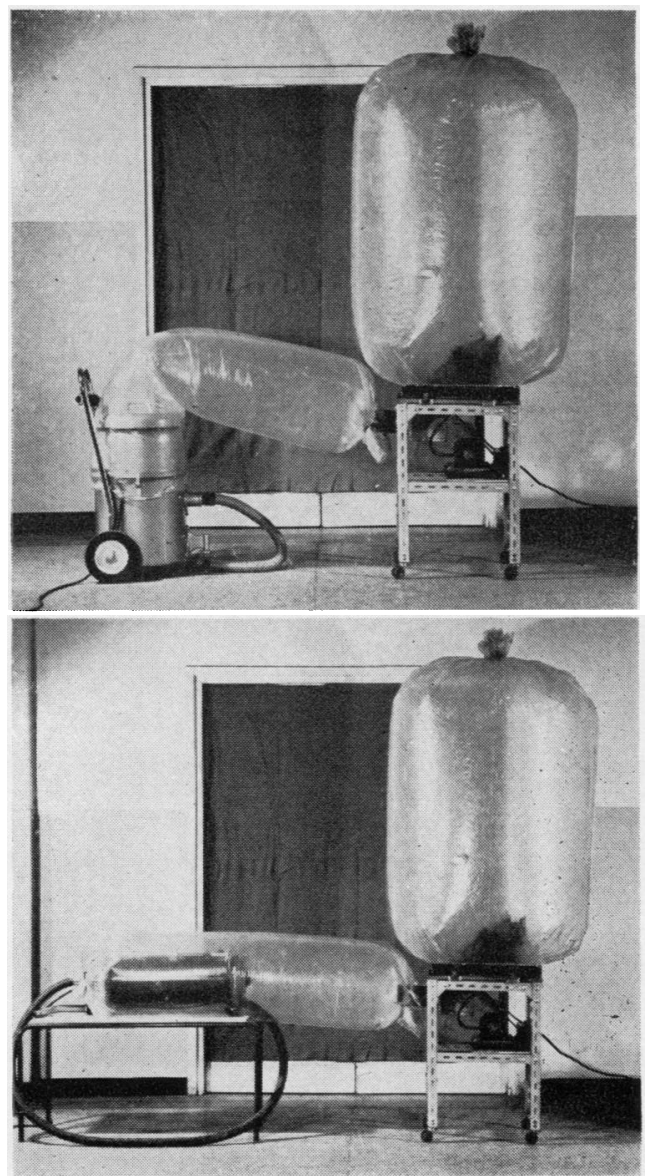

FIG. 4 
$5 \mathrm{ft}$. long attached to the metal duct leading to the interior of the reservoir through the opening in the table top beside the slit sampler. Into the free end of this bag can be tied by means of a length of rubber tubing, as seen in Fig. 2, the outlet of the largest machine examined, the whole of a cylinder-type machine (see Fig. 4) or of a suction-polisher, of which the brushes alone remain outside. The sequence of operations in a test run is as follows:

1 To ensure a free flow of air through the machine under test, compacted masses of dust and fluff are removed from the dust container, but dirt clinging to the filtering surfaces is not disturbed.

2 The cleaner is connected to the electricity supply and fastened inside the receiving tube.

3 The slit sampler is loaded with a plate of culture medium.

4 The reservoir is clamped down and evacuated of all contained air by means of a second vacuum cleaner whose nozzle is inserted through a second opening in the table top, normally kept stoppered.

5 The cleaner under test is allowed to run for two minutes, driving out any residual air and any dust particles from the inside of the apparatus.

6 The joint between the reservoir and the table top breaks to allow the escape of surplus air, but as the cleaner is switched off, the reservoir is clamped down to hold the last $20 \mathrm{cu}$. $\mathrm{ft}$.

7 A $5 \mathrm{cu}$. $\mathrm{ft}$. sample is then run through the slit sampler, the switch for this being outside the reservoir.

In order to discover whether the apparatus was capable of demonstrating the relative filtration efficiency of a number of cleaners, some preliminary runs were carried out on machines which could be expected to yield air in descending grades of purity relative to one another. An old cylinder cleaner with one layer of filtering material gave four colonies in $5 \mathrm{cu}$. $\mathrm{ft}$. An older domestic vacuum cleaner of the hanging-bag type gave 66 colonies in the same volume of air, rather more than the number obtained from a sample of the air in the room. Lastly, a cylindertype cleaner was stripped of all its filtering media, and in place of the dust bag there was fitted a cloth bag made of $2 \mathrm{~mm}$. mesh curtain netting. This bag was filled with the dust from the bag it replaced. A $5 \mathrm{cu}$. $\mathrm{ft}$. sample of the air yielded 510 colonies. The fouling of the apparatus resulting from these and subsequent tests was removed by washing the polyethylene tubes with soap and water and polishing with an antistatic polish.

In the actual investigation, the sequence of operations described above was performed three times for each cleaner at each test. No dirt was drawn in, tools were detached, and the air entry kept well above floor level.
AIR DISTURBANCE The high-velocity jet discharge 으 of many vacuum cleaners has already been men- $\vec{F}$ tioned, and a method was also devised to assess and $\stackrel{0}{\rightarrow}$ compare the extent of air disturbance caused by each. In a small room, $10 \mathrm{ft}$. by $12 \mathrm{ft}$., furnished only with $\frac{\bar{\sigma}}{\bar{N}}$ a bed, locker, chair, and chest of drawers, the slit $\frac{5}{\sigma}$ sampler without the reservoir was set up on one side $\stackrel{\mathbb{Q}}{\triangle}$ of the bed. The cleaner under test stood on the other $\approx$ side, between the bed and the window. To eliminate $\vec{O}$ disturbance due to suction, the end of the hose was hung out of the window, the resulting gap being $\vec{\omega}$ filled with broad adhesive tape. The operator sat at $\stackrel{\Omega}{\Omega}$ arm's length from the sampler, moving only as much as was necessary to change plates, having switches at $\overrightarrow{\vec{A}}$ hand to control both the cleaner and the sampler. After allowing 15 minutes for disturbance due to setting up the apparatus to subside, a $5 \mathrm{cu}$. $\mathrm{ft}$. sample $ᄋ$ of room air was taken. The cleaner was then switched on for four minutes, switched off and a second $\vec{c}$ sample of room air taken. Six further samples were taken at intervals of 15 minutes during the period of one and a half hours from the operation of the cleaner. Colony counts demonstrated the degree of air disturbance, and its subsequent settling.

CHOICE OF A VACUUM CLEANER The results obtained by these methods have been fully reported elsewhere (Bate, 1961) and need not be repeated here, but in the light of this work it is possible to make some suggestions as to the choice of vacuum cleaner for ward use. The first consideration should be the method of finally disposing of the collected dust, and preference should be given to those machines in which a disposable paper bag is provided for this purpose. Secondly, performance figures should be studied; they are readily available. A high rate of air displacement is desirable; a high closed vacuum is less important, but the most satisfactory index of performance is the figure for suction power, measured in foot-pounds per second according to a formula laid down by the British Standards Institution (1958). This is now available for most cleaners. Filtering efficiency may be considered adequate if there are not less than two layers of filtering material actually within the body of the machine, on the input side of the air impeller, and separate from one another so that failure of the first layer is immediately apparent on inspection of the second. Finally, the exhaust jet should be well diffused, and any diffusing device should preferably form an integral part of the machine, or be detachable only with difficulty.

I am very much indebted to Mr. M. C. Hardie, of the Division of Hospital Facilities of King Edward's Hospital Fund for London, for putting at my disposal a very large amount of information about floors and their cleaning. 
The slit sampler used in the investigation was lent to me by the Wright-Fleming Institute of Microbiology, St. Mary's Hospital, to which I am most grateful; as also to Professor R. E. O. Williams for his helpful criticisms.

\section{REFERENCES}

Adams, R., Fahlman, B., Dube, E. W., Dube, F. J. C., and Read, S. (1959). J. Amer. med. Ass., 169, 1557.
Bate, J. G. (1961). Lancet, 1. To be published.

- and James, U. (1958). Ibid., 2, 713.

Bourdillon, R. B., Lidwell, O. M., Lovelock, J. E., and others. (1948). Spec. Rep. Ser. med. Res. Coun. (Lond.), No. 262.

British Standards Institution. (1958). Electric Vacuum Cleaners for Use in Hospitals, (B.S. 3028: 1958).

Cruickshank, R. (1935). J. Path. Bact., 41, 367.

Garrod, L. P. (1944). Brit. med. J., 1, 245.

Gershenfeld, L., and Witlin, B. (1955). Soap, 31, (12), 189.

Rubbo, S. D. (1948). J. Hyg. (Camb.), 46, 158.

Sykes, G. (1958). Disinfection and Sterilization. Spon, London. 